\begin{tabular}{|c|l|}
\hline Title & FACTOR ENDOWMENTS AND THE PATTERN OF COMMODITY AND FACTOR TRADE \\
\hline Sub Title & \\
\hline Author & 大山, 道廣(OHYAMA, Michihiro) \\
\hline Publisher & Keio Economic Society, Keio University \\
\hline Publication year & 1989 \\
\hline Jtitle & Keio economic studies Vol.26, No.1 (1989. ),p.19- 29 \\
\hline JaLC DOI & \\
\hline Abstract & $\begin{array}{l}\text { This paper generalizes the standard multi-commodity, multi-factor model of trade to allow for } \\
\text { international factor mobility and investigates the relationship between factor endowments and } \\
\text { the pattern of commodity and factor trade. In the absence of international differences in } \\
\text { technologies and preferences, the pattern of commodity trade is shown to be determined by } \\
\text { differences in the endowments of internationally immobile factors. In contrast, the pattern of } \\
\text { factor trade and the balance of commodity or factor trade are unambiguously dependent on } \\
\text { differences in the endowments of internationally mobile factors. }\end{array}$ \\
\hline Notes & \begin{tabular}{l} 
Journal Article \\
\hline Genre
\end{tabular} \\
\hline URL & \begin{tabular}{l} 
https://koara.lib.keio.ac.jp/xoonips/modules/xoonips/detail.php?koara_id=AA00260492-1989000 \\
\hline
\end{tabular} \\
\hline
\end{tabular}

慶應義塾大学学術情報リポジトリ(KOARA)に掲載されているコンテンツの著作権は、それぞれの著作者、学会または出版社/発行者に帰属し、その権利は著作権法によって 保護されています。引用にあたっては、著作権法を遵守してご利用ください。

The copyrights of content available on the KeiO Associated Repository of Academic resources (KOARA) belong to the respective authors, academic societies, or publishers/issuers, and these rights are protected by the Japanese Copyright Act. When quoting the content, please follow the Japanese copyright act. 


\title{
FACTOR ENDOWMENTS AND THE PATTERN OF COMMODITY AND FACTOR TRADE
}

\author{
Michihiro OHYAMA*
}

Abstract. This paper generalizes the standard multi-commodity, multi-factor model of trade to allow for international factor mobility and investigates the relationship between factor endowments and the pattern of commodity and factor trade. In the absence of international differences in technologies and preferences, the pattern of commodity trade is shown to be determined by differences in the endowments of internationally immobile factors. In contrast, the pattern of factor trade and the balance of commodity or factor trade are unambiguously dependent on differences in the endowments of internationally mobile factors.

\section{INTRODUCTION}

In the traditional theory of international trade it is customary to assume that the factors of production are prohibited to move from country to country for some reason or another. This assumption of factor immobility plays an important role especially in the theory of comparative advantage. The standard Heckscher-Ohlin theory explains the pattern of commodity trade in terms of factor endowment proportions of different countries on the assumption that no factors of production are internationally mobile. (For an excellent recapitulation and generalization of the doctrine, see Dixit and Woodland (1982)). In reality, however, some factors are known to move across national borders as exemplified by the international transfer of entrepreneurial resources and labor services (often through direct investment) as well as by international capital movements.

Furthermore, it is at times difficult or even misleading to explain the observed patterns of trade without reference to international factor mobility. For instance, the standard Heckscher-Ohlin theorem is contradicted by the well known observation by Leontief (1954) that the United States, apparently a capital rich country, had comparative advantage in labor intensive commodities rather than in capital intensive commodities. It is also at variance with the recent development of capital intensive industries such as steel, chemical or shipbuilding in some of the labor abundant, newly industrializing countries (notably.Korea and Taiwan). The failure of the standard theory to explain these facts may be attributable, among other things, to its basic assumption that national boundaries delimit the areas within which factors are mobile. In the world where capital is internationally mobile, the employment of capital in a country is not constrained by its

* I am indebted to Professors R. W. Jones, A. Dixit, E. Helpman and M. C. Kemp for valuable comments. 
endowment of capital (i.e., the amount of capital owned by its residents). Therefore, while a capital rich country may export capital and import capital intensive commodities, a labor abundant country may import capital and export capital intensive commodities.

The purpose of this paper is to extend the Heckscher-Ohlin theory to the situation where some (but not all) factors of production are internationally mobile. In our view, the problem of comparative advantage under factor mobility has received less attention than it deserves in the related literature on international capital mobility. Jones and Ruffin (1975) and Ferguson (1978) provide interesting studies focusing on the pattern of commodity trade under international capital mobility. But their analyses are confined to the familiar two-commodity, towfactor model of international trade in which capital mobility is a perfect substitute for commodity trade in the absence of technological differences. Thus they deviate form the main theme of the Heckscher-Ohlin theory which ascribes the positions of comparative advantage to differences in factor endowments. ${ }^{1}$ More recently, Svensson (1984) and Ethier and Svensson (1986) attempt to generalize this theme directly, but their conclusion is rather weak in the sense that it requires a substantial reinterpretation of "trade pattern." In this paper we also generalize the standard multi-commodity, multi-factor model to allow for international factor mobility and, in the wake of Dixit and Woodland (1982), investigate the relationship between factor endowments and the pattern of commodity and factor trade in an alternative manner.

The plan of the paper is as follows. In Section 2, we introduce a two country model of international trade in which some factors, as well as commodities, are internationally mobile. Assuming identical technologies with constant returns to scale and identical homothetic preferences for commodities, we elucidate the effects of small endowment changes in one of the countries on its excess supplies in the free trade international equilibrium. In section 3 , we scrutinize their implications for the dependence of trade patterns on factor endowments. The pattern of commodity trade is shown to be basically determined by differences in the endowment of internationally immobile factors except for singular cases. Obviously, this observation is nothing but an extension of the Heckscher-Ohlin theorem to the present context. In contrast, the pattern of factor trade depends most clearly on differences in the endowment of internationally mobile factors and less clearly on those in the endowments of immobile factors. We also find that the structure of the balance of payments (the balance of commodity or factor trade) is unambiguously affected by the endowments of mobile factors. In Section 4, we sharpen some of these results in the context of a simple two-commodity, twofactor model of international trade.

\footnotetext{
1 Hence, it is technological differences between countries which give rise to comparative advantage positions in their model.
} 


\section{A MODEL OF COMMODITY AND FACTOR TRADE}

In this section, we develop a general framework to investigate the relationship between factor endowments and trade patterns in the world where some factors are internationally mobile. For simplicity, suppose that the world is composed of two countries, home and foreign (or overseas). Each country is potentially able to produce $n$ commodities using $m$ internationally immobile factors and $l$ internationally mobile factors under given technologies. Its endowment of every factor is given exogenously and perfect competition is assumed to prevail in all markets.

The following basic notation is used to denote the variables of the home country.

$$
\begin{array}{ll}
Y=\left(Y_{1}, \cdots, Y_{n}\right): & \text { supply vector of commodities. } \\
X=\left(X_{1}, \cdots, X_{n}\right): & \text { demand vector of commodities. } \\
N=\left(N_{1}, \cdots, N_{M}\right): & \text { endowment vector of immobile factors. } \\
K=\left(K_{1}, \cdots, K_{l}\right): & \text { endowment vector of mobile factors. } \\
V=\left(V_{1}, \cdots, V_{l}\right): & \text { input vector of mobile factors. } \\
p=\left(p_{1}, \cdots, p_{n}\right): & \text { price vector of commodities. } \\
w=\left(w_{1}, \cdots, w_{m}\right): & \text { price vector of immobile factors. } \\
r=\left(r_{1}, \cdots, r_{l}\right): & \text { price vector of mobile factors. } \\
I: & \text { aggregate disposable income. }
\end{array}
$$

We indicate the corresponding foreign variables by asterisks. The endowment of a factor in each country is defined here as the amount of the factor owned by its residents. Needless to say, it generally differs from the input (or employment) of the factor in the country if the factor is internationally mobile.

Let us assume that the prices of internationally immobile factors are always adjusted to clear the domestic markets of those factors in each country. We may then express them generally as functions of the prices of commoditites and mobile factors, and of the endowments of immobile factors, i.e.,

$$
\begin{aligned}
& w=w(p, r, N), \\
& w^{*}=w^{*}\left(p^{*}, r^{*}, N^{*}\right) .
\end{aligned}
$$

We may also write the supplies of commodities and the inputs of internationally mobile factors as functions of the same variables, i.e.,

$$
\begin{aligned}
& Y=Y(p, r, N), \\
& V=V(p, r, N), \\
& Y^{*}=Y^{*}\left(p^{*}, r^{*}, N^{*}\right), \\
& V^{*}=V^{*}\left(p^{*}, r^{*}, N^{*}\right) .
\end{aligned}
$$

The consumers of each country are assumed to possess identical and homothetic preferences for commodities. This enables us to express their demands for 
commodities as functions of commodity prices and aggregate disposable income, i.e.,

$$
\begin{aligned}
& X=D(p, I), \\
& X^{*}=D^{*}\left(p^{*}, I^{*}\right),
\end{aligned}
$$

where, in the long-run equilibrium with zero profits,

$$
\begin{aligned}
& I=w N+r K, \\
& I^{*}=w^{*} N^{*}+r^{*} K^{*} .
\end{aligned}
$$

In view of (1) and (2), we may rewrite (7) and (8) as

$$
\begin{aligned}
& X=X(p, r, N, K), \\
& X^{*}=X^{*}\left(p^{*}, r^{*}, N^{*}, K^{*}\right) .
\end{aligned}
$$

To ease notation, define the excess supply vectors by

$$
\begin{aligned}
& E=Y-X=E(p, r, N, K), \\
& F=K-V=F(p, r, N, K), \\
& E^{*}=Y^{*}-X^{*}=E^{*}\left(p^{*}, r^{*}, N^{*}, K^{*}\right), \\
& F^{*}=K^{*}-V^{*}=F^{*}\left(p^{*}, r^{*}, N^{*}, K^{*}\right) .
\end{aligned}
$$

By virtue of (2) $-(6),(9)$ and (10), the excess supplies of each country are functions of the prices of commoditites and mobile factors and of factor endowments.

Suppose that initially the home and foreign countries have the same factor endowment proportions, or $N=\lambda N^{*}$ and $K=\lambda K^{*}$ ( $\lambda$ is a positive scalar). Following the tradition of the Heckscher-Ohlin theory of international trade, let us also assume constant returns to scale in production, identical technologies, identical homothetic preferences across countries. Given the same commodity and factor prices, the size of the foreign economy would be exactly $\lambda$ times that of the home economy. Hence, we may write

$$
\begin{aligned}
& E^{*}\left(p, r, N^{*}, K^{*}\right)=\lambda E(p, r, N, K), \\
& F^{*}\left(p, r, N^{*}, K^{*}\right)=\lambda F(p, r, N, K) .
\end{aligned}
$$

The same relationships also hold for the partial differentiation of excess supply functions with respect to prices. Thus

$$
\begin{aligned}
& E_{P}^{*}=\lambda E_{p}, \\
& E_{r}^{*}=\lambda E_{r}, \\
& V_{p}^{*}=\lambda V_{p}, \\
& V_{r}^{*}=\lambda V_{r},
\end{aligned}
$$

where subscripts signify partial differentiations. 
Under autarky, the equilibrium prices of the home country, $\bar{p}$ and $\bar{r}$, are determined by the conditions

$$
\begin{aligned}
& E(\bar{p}, \bar{r}, N, K)=0, \\
& F(\bar{p}, \bar{r}, N, K)=0,
\end{aligned}
$$

and the equilbrium prices of the foreign country, $\bar{p}^{*}$ and $\vec{r}^{*}$, by the conditions

$$
\begin{aligned}
& E^{*}\left(\bar{p}^{*}, \bar{r}^{*}, N^{*}, K^{*}\right)=0, \\
& F^{*}\left(\bar{p}^{*}, \bar{r}^{*}, N^{*}, K^{*}\right)=0 .
\end{aligned}
$$

Under free commodity and factor trade, international equilibrium prices, $p^{f}$ and $\boldsymbol{r}$, are determined by the conditions

$$
\begin{aligned}
& E\left(p^{f}, r^{f}, N, K\right)+E^{*}\left(p^{f}, r^{f}, N^{*}, K^{*}\right)=0, \\
& F\left(p^{f}, r^{f}, N, K\right)+F^{*}\left(p^{f}, r^{f}, N^{*}, K^{*}\right)=0 .
\end{aligned}
$$

We assume that eqs. (11) and (12) hold in the initial situation. The autarkic equilibrium of one country then implies that of another and therefore the international equilibrium of the two countries. With no international trade or factor movements actually taking place, the relative prices of commodities and factors are equalized internationally. Using a common numeraire we have

$$
\begin{aligned}
& \bar{p}=\bar{p}^{*}=\mathrm{p}^{f}, \\
& \bar{r}=\bar{r}^{*}=r^{f},
\end{aligned}
$$

in the initial situation.

Starting from this situation we wish to consider the effects of changes in the home country's factor endowments on the pattern of free trade both in commodities and factors. For this purpose, differentiate totally the conditions for international equilibrium, (21) and (22), to obtain ${ }^{2}$

$$
\begin{aligned}
& \left(E_{p}+E_{p}^{*}\right) d p^{f}+\left(E_{r}+E_{r}^{*}\right) d r^{f}-E_{N} d N+E_{K} d K=0, \\
& \left(V_{p}+V_{p}^{*}\right) d p^{f}+\left(V_{r}+V_{r}^{*}\right) d r^{f}-d K+V_{N} d N=0 .
\end{aligned}
$$

Making use of (13) $-(16)$, we get

$$
\begin{aligned}
& (1+\lambda)\left(E_{p} d p^{f}+E_{r} d r^{f}\right)+E_{N} d N+E_{K} d K=0, \\
& (1+\lambda)\left(V_{p} d p^{f}+V_{r} d r^{f}\right)-d K+V_{N} d N=0 .
\end{aligned}
$$

These equations implicitly define the changes in commodity and factor prices resulting from changes in the home country's factor endowments. It is not

\footnotetext{
2 We assume throughout the paper that excess supply functions are differntiable with respect to all their arguments. If the number of commodities is greater than the number of internationally immobile factors (i.e., $n>m$ ), the supplies of commodities may not be uniquely determined for given prices. We exclude this "singular" case from our analysis arbitrarily. Jones and Ruffin (1975) and Ferguson (1978) deal with the "Ricardian" case in which $n=2$ and $m=1$.
} 
necessary to derive their explicit solution for the present purpose.

Since there is not trade in the initial equilibrium, the home country's excess supplies in the new international equilibrium must be equal to the changes in its excess supplies from their initial (zero) values. Taking account of (25) and (26), we may express them as

$$
\begin{aligned}
d E & =E_{p} d p^{f}+E_{r} d r^{f}+E_{N} d N+E_{K} d K \\
& =[\lambda /(1+\lambda)]\left(E_{N} d N+E_{K} d K\right) \\
d F & =-V_{p} d p^{f}-V_{r} d r^{f}+d K-V_{N} d N \\
& =[\lambda /(1+\lambda)]\left(d K-V_{N} d N\right)
\end{aligned}
$$

These are the fundamental equations relating the home country's external trade with its factor endowments. ${ }^{3}$ They show that the sign pattern of the home country's excess supplies in the new equilibrium coincide with that of the changes in its excess supplies caused by changes in factor endowments at the initial commodity and factor prices. It should be noted that all excess supplies are scaled down equiproportionately as a result of the equilibrating price changes.

\section{FACTOR ENDOWMENTS AND THE PATTERN OF TRADE}

In the preceding section, we derived the expressions for the effects of endowment changes upon the home country's commodity and factor trade. We are now in the position to examine them more closely. It is natural to deal with internationally mobile and immobile factors separately.

Let us begin by considering the relationship between the endowments of immobile factors and the pattern of commodity trade. Needless to say, it occupies a central position in the Heckscher-Ohlin theory of international trade. Setting $d K=0$ in (27) and taking account of (3), (4) and (9), we obtain

$$
\begin{aligned}
d E & =[\lambda /(1+\lambda)] E_{N} d N \\
& =[\lambda /(1+\lambda)]\left(Y_{N}-D_{I} w\right) d N .
\end{aligned}
$$

This shows that the pattern of commodity trade in the new international equilibrium is indicated by the sign structure of $Y_{N}-D_{I} w$. The $(j, i)$ element of matrix $\left(Y_{N}-D_{I} w\right)$ may be written as

$$
\partial E_{j} / \partial N_{i}=\partial Y_{j} / \partial N_{i}-w_{i} D_{j} / I
$$

using the relationship, $\partial D_{j} / \partial I=D_{j} / I$, applicable when consumers' preferences are homothetic. It is convenient to express this in terms of elasticities. Let us define the Rybcynski elasticity of commodity $j$ with respect to the endowment of factor $i$ by

$$
\gamma_{j} i=\left(N_{i} / Y_{j}\right)\left(\partial Y_{j} / \partial N_{i}\right) \text {. }
$$

Also define the share of factor $i$ in national incorne as

3 They extend the result of Dixit and Woodland (1982, p. 208) to the present context. 


$$
\theta_{i}=w_{i} \mathrm{~N}_{i} / I .
$$

Recall that there is no trade in the initial equilbrium, so $D_{j}=Y_{j}$. Then (30) becomes

$$
\partial E_{j} / \partial N_{i}=\left(\gamma_{j} i-\theta_{i}\right) Y_{j} / N_{i} .
$$

We may say from this that commodity $j$ will be exported when the endowment of immobile factor $i$ is increased if the Rybczynski elasticity of commodity $j$ exceeds the share of factor $i$ in national income. This is a straightforward extension of the Heckscher-Ohlin theorem as recapitualated by Dixit and Norman (1982) to the world where some factors are internationally mobile.

It may be useful to consider the implications of (31) in the special case where the numbers of commodities and immobile factors are equal $(n=m)$ and where there is no joint production. If there is an ordering of commodities and factors such that the square matrix of Rybczynski elasticities, $\left[\gamma_{j} i\right]$, has diagonal elements all greater than unity and off-diagonal elements all negative, commodity $i$ will be exported and all other comodities imported when the endowment of immobile factor $i$ is increased. As we shall see in the next section, there is indeed such an ordering of commodities and factors in the case where $m=n=2$ provided that factor intensity differs from commodity to commodity. An increase in the endowment of an immobile factor will lead to the export of the commodity which uses the factor relatively intensively and the import of the other commodity in this special case. Thus the gist of the familiar Heckscher-Ohlin theorem is shown to remain valid as it relates the pattern of commodity trade with the endowments of immobile factors regardless of the presence of any number of internationally mobile factors. The relationship between the pattern of trade and the endowments of immobile factors is not essentially affected by the introduction of mobile factors even in the case where the number of commodities differ from that of immobile factors. ${ }^{4}$

Our next concern is to see how the pattern of factor trade is related to the endowments of immobile factors. Set $d K=0$ in (28) to get

$$
d F=-[\lambda /(1+\lambda)] V_{N} d N .
$$

The pattern of factor movements is thus shown to coincide with the sign pattern of matrix $-V_{N}$. Very little is known of this matrix in the literature. Consider again the special case where the numbers of commodities and factors are equal $(n=m)$ and suppose that the matrix of Rybczynski elasticities has diagonal elements all greater than unity and off-diagonal elements all negative. We may then presume that an increase in the endowment of immobile factor $i$ increases the output of commodity $i$ and decreases that of all other commodities thereby inducing the inflow of those mobile factors which are used "intensively" in the production of

4 As noted before, the effects of endowment changes on the pattern of trade may become indeterminate if the number of commoditites exceeds that of immobile factors. But we have the same problem in the standard model of international trade where no factors are internationally mobile. 
commodity $i$ and the outflow of all other factors. We shall illustrate this point in the context of a simple $2 \times 3$ model in the next section.

Let us now turn to the effects of changes in the endowments of mobile factors on the pattern of commodity and factor trade. They are simpler and easier to work out than the effects of endowment changes of immobile factors. Setting $d N=0$ in (27) and (28) and making use of (3), (7) and (9), we get

$$
\begin{aligned}
& d E=-[\lambda /(1+\lambda)] D_{I} r d K, \\
& d F=[\lambda /(1+\lambda)] d K .
\end{aligned}
$$

The following conclusions are immediate from these equations. First, an increase in the endowments of each mobile factor induces all commoditites to be imported. In fact, it increases the national income and therefore the demands for all commodities (remember that preferences are homothetic) at the initial prices without affecting their supplies. Thus it causes all commodities to be in excess demand at the initial prices and to be imported even after the prices have changed to reestablish international equilibrium. Secondly, an increase in the endowment of each mobile factor results in its outflow but leaves all other mobile factors unaffected. This result is due to the fact that the input of each factor remains unaffected at the initial prices.

It should be noted here that an increase in the endowment of a mobile factor causes the balance of commodity trade to turn to a deficit and the balance of factor (service) trade to exhibit a surplus. From (33) and (34) we have

$$
p d E+r d F=[\lambda /(1+\lambda)]\left(1-p D_{I}\right) r d K=0 .
$$

This means that the deficit in the balance of commodity trade must be exactly matched by the surplus in the balance of factor trade to maintain the equilibrium of the current account.

\section{ILLUSTRATION BY A $2 \times 3$ MODEL}

To bring into sharper focus some of the points made in the previous analysis we turn to a $2 \times 3$ model of commodity and factor trade in this section. Suppose that the home and foreign countries produce two commodities labelled 1 and 2 by means of three factors labeled 1,2 and $k$. Of the three factors of production, 1 and 2 are internationally immobile and $k$ moves freely across the national border. Needless to say, this is a special case of the model described and analysed in the previous two sections and its structure has been investigated recently by such authors as Batra and Casas (1976), Ruffin (1981), Suzuki (1983), Jones and Easton (1983) and Hill and Mendex (1983).

In view of the symmetry of our world, it will suffice to consider only one of the two countries and so we shall henceforth concentrate on the home country. Let $w_{1}$, $w_{2}$ and $r$ denote the price of factors 1,2 and $k$, and let $p_{1}$ and $p_{2}$ the prices of 
commodities 1 and 2 respectively. The competitive forces entail the zero profit conditions:

$$
\begin{aligned}
& a_{11} w_{1}+a_{12} w_{2}+a_{k 1} r=p_{1}, \\
& a_{12} w_{1}+a_{22} w_{2}+a_{k 2} r=p_{2}
\end{aligned}
$$

where $a_{i j}$ is the input of factor $i$ per unit output of commodity $j(i=1,2, k, j=1,2)$. Firms are assumed to operate under constant returns to scale and determine input coefficients, $a_{i j}$, so as to minimize the unit cost of production taking factor prices as given. Thus, $a_{i j}$ 's are functions of $w_{1}, w_{2}$ and $r$, which may be written as

$$
a_{i j}=b_{i j}\left(w_{1}, w_{2}, r\right) . \quad i=1,2, k ; j=1,2
$$

Given the prices of commodities and mobile factor, $p_{1}, p_{2}$ and $r$, equations (35), (36) and (37) are taken to determine the prices of immobile factors, $w_{1}$ and $w_{2}$, and the input coefficients, $a_{i j}$. This means that $w_{1}, w_{2}$ and $a_{i j}$ 's are functions of $p_{1}, p_{2}$ and $r$, or

$$
\begin{array}{ll}
w_{i}=w_{i}\left(p_{1}, p_{2}, r\right), & i=1,2 \\
a_{i j}=a_{i j}\left(p_{1}, p_{2}, r\right) & i=1,2 ; j=1,2, k
\end{array}
$$

in the present model. ${ }^{5}$

Let $N_{1}$ and $N_{2}$ denote the endowments of immobile factors 1 and 2, and let $Y_{1}$ and $Y_{2}$ the outputs of commodities 1 and 2 respectively. Given prices, the outputs of commodities are adjusted to clear the markets for immobile factors. Hence, we have the full employment conditions:

$$
\begin{aligned}
& a_{11} Y_{1}+a_{12} Y_{2}=N_{1}, \\
& a_{21} Y_{1}+a_{22} Y_{2}=N_{2} .
\end{aligned}
$$

Given the supplies of commodities, the input, $V$, of mobile factor $k$ is given by

$$
a_{k 1} Y_{1}+a_{k 2} Y_{2}=V \text {. }
$$

Thus $Y_{1}, Y_{2}$ and $V$ are functions of $p_{1}, p_{2}, r, N_{1}$ and $N_{2}$, or

$$
\begin{aligned}
& Y_{j}=Y_{j}\left(p_{1}, p_{2}, r, N_{1}, N_{2}\right), \quad j=1,2 \\
& V=V\left(p_{1}, p_{2}, r, N_{1}, N_{2}\right) .
\end{aligned}
$$

Note that the general results obtained previously are directly applicable to the present model if we assume that the preferences for commoditites are everywhere identical and homothetic.

Now let us use this model to consider the effects of changes in the endowments of immobile factors upon the pattern of commodity and factor trade. Suppose that

\footnotetext{
5 It should be noted that the prices of immobile factors are generally dependent on their endowments as shown in eqs. (1) and (2). This dependence disappears in the present setup only because we have constant returns to scale in production and the number of commodities and immobile factors are equal.
} 
immobile factor 1 is used relatively intensively in the production of commodity 1 and factor 2 in the production of commodity 2 , i.e.,

$$
a_{11} / a_{12}>a_{21} / a_{22}
$$

for all factor prices. To interpret (29) or (32) in the present context, it is necessary to investigate the dependence of $Y_{1}, Y_{2}$ and $V$ on $N_{1}$ and $N_{2}$ in (43) and (44).

Assuming that all prices, and therefore, all input coefficients are given, differentiate equations (40)-(42) to get

$$
\begin{aligned}
& \lambda_{11} \hat{Y}_{1}+\lambda_{12} \hat{Y}_{2}=\hat{N}_{1}, \\
& \lambda_{21} \hat{Y}_{2}+\lambda_{22} \hat{Y}_{2}=\hat{N}_{2}, \\
& \lambda_{k 1} \hat{Y}_{1}+\lambda_{k 2} \hat{Y}_{2}=\hat{V}
\end{aligned}
$$

where $\lambda_{i j}$ denotes a fraction of fractor $i$ employed in the production of commodity $j$ and circumflex ( $)$ indicates the rate of change of the variable. For instance, $\lambda_{11}=a_{11} Y_{1} / N_{1}$ and $\hat{Y}_{1}=d Y_{1} / Y_{1}$. Solving them, we obtain

$$
\begin{aligned}
& \hat{Y}_{1}=\left(\lambda_{22} \hat{N}_{1}-\lambda_{12} \hat{N}_{2}\right) /|\lambda|, \\
& \hat{Y}_{2}=-\left(\lambda_{21} \hat{N}_{1}-\lambda_{11} \hat{N}_{2}\right) /|\lambda|, \\
& \hat{V}=\left(\left|\lambda_{2}^{k}\right| \hat{N}_{1}+\left|\lambda_{1}^{k}\right| \hat{N}_{2}\right) /|\lambda|
\end{aligned}
$$

where

$$
\begin{aligned}
& |\lambda|=\lambda_{11} \lambda_{22}-\lambda_{21} \lambda_{12}, \\
& \left|\lambda_{1}^{k}\right|=\lambda_{11} \lambda_{k 2}-\lambda_{12} \lambda_{k 1}, \\
& \left|\lambda_{2}^{k}\right|=\lambda_{22} \lambda_{k 1}-\lambda_{21} \lambda_{k 2} .
\end{aligned}
$$

By definition we may write

$$
|\lambda|=\lambda_{11}-\lambda_{21}=\lambda_{22}-\lambda_{12}
$$

By virtue of $(\mathrm{A})$, this implies that $|\lambda|$ takes on a positive value smaller than unity.

Let us first consider eqs. (48) and (49). It is easy to see from them that an increase in the endowment of an immobile factor brings about a more than proportionate increase in the output of the commodity which uses it intensively in production and a decrease in the output of the other commodity. Suppose as before that the foreign country has the same technologies, preferences and factor proportions as the home country in the initial situation. This implies that there is no trade between the two countries. Eqs. (48) and (49), together with eq. (31) in the preceding section, tell us that if, starting from this situation, the home country's endowment of an immobile factor, say 1, increases, the home country will end up exporting commodity 1 and importing commodity 2 . This result is in perfect consonance with the message of the traditional Heckscher-Ohlin theory of international trade. In fact, it extends the latter to the case in which there is a third, and internationally mobile factor of production. 
Turning to eq. (50), we observe that the effect of an increase in the endowment of an immobile factor on the aggregate input of mobile factor $k$ differs depending on whether the expanding sector uses factor $k$ vis-a-vis the other immobile factor more intensively than the contracting sector. For instance, an increase in the endowment of factor 1 increases the input of factor $k$ if an only if $\left|\lambda_{2}^{k}\right|>0$, or $\lambda_{k 1} / \lambda_{21}>\lambda_{k 2} / \lambda_{22}$. Note that as the endowment of factor 1 increases, the output of commodity 1 increases and that of commodity 2 decreases. Given the endowment of factor 2, the input of factor $k$ increases if an only if more of factor $k$ is used in combination with one unit of factor 2 in the production of commodity 1 than in the production of commodity 2 . Similarly, an increase in the endowment of factor 2 increases the input of factor $k$ if and only if $\left|\lambda_{1}^{k}\right|>0$, or $\lambda_{k 2} / \lambda_{12}>\lambda_{k 1} / \lambda_{11}$.

In view of eq. (32) in the preceding section, we may infer from the foregoing analysis that an increase in the endowment of any immobile factor brings about an inflow of mobile factor $k$ starting from the initial situation of no trade if and only if

$$
\lambda_{11} / \lambda_{12}>\lambda_{k 1} / \lambda_{k 2}>\lambda_{21} / \lambda_{22}
$$

This condition means that factor $k$ is the "middle factor" in the words of Jones and Eastman (1983) occupying an intermediate position between the two "extreme" factors 1 and 2 in factor intensity ranking. If it fails to be satisfied, an increase in the endowment of an immobile factor may give rise to an outflow of factor $k$.

Keio University

\section{REFERENCES}

Batra, R. N. and F. R. Casas, 1976, "A Synthesis of The Heckscher-Ohlin and the Neoclassical Models of International Trade," Journal of International Economics, Vol. 6, 21-38.

Dixit, A. and A. Woodland, 1982, "The Relationship between Factor Endowments and Commodity Trade," Journal of International Economics, Vol. 13, 201-214.

Ethier, W. J. and L. E. O. Svensson, 1986, "The Theorems of International Trade with Factor Mobility," Journal of international Economics, Vol. 20, $21-42$.

Ferguson, D. G., 1978, "International Capital Mobility and Comparative Advantage-The Twocountry, Two-factor Case," Journal of International Economics, Vol. 8, 373-396.

Hill, J. K. and A. Mendes, 1983, "Factor Mobility and the General Equilibrium Model of Productions," Journal of International Economics, Vol. 19, 18-26.

Jones, R. W. and R. Ruffin, 1975, "Trade Patterns with Capital Mobility," in M. Parkin and A. R. Nobay eds. Current Economic Problems: The Proceedings of the Association of University Teachers of Economics, Manchester (Cambridge University Press, London), 307-332.

Jones, R. W. and S. T. Easton, 1983, "Factor Intensities and Factor Substitution in General Equilibrium," Journal of International Economics, Vol. 19, 65-99.

Leontief, W. W., 1954, "Domestic Production and Foreign Trade: The American Capital Position Reexamined," Economia Internazionale, Vol. 7, 9-45.

Ruffin, R., 1981, "Trade and Factor Movements with Three Factors and Two Goods," Economics Letters, Vol. 7, 177-82.

Suzuki, K., 1983, "A Synthesis of the Heckscher-Ohlin and the Neoclassical Models of International Trade: A Comment," Journal of International Economics, Vol. 14, 141-144.

Svensson, L. E. O., "1984, Factor Trade and Goods Trade," Journal of International Economics, Vol. $16,365-378$. 